\title{
Pendampingan Pengelolaan Media Promosi Bagi UMKM Prima Laundry Malang
}

\author{
Rizky Kurniawan Murtiyanto, ${ }^{*}$, Shinta Maharani Trivena ${ }^{2}$, Lina Budiarti ${ }^{3}$, Abdul Waris ${ }^{4}$, Umi Khabibah $^{5}$ \\ 1,2,3,4,5 Jurusan Administrasi Niaga, Politeknik Negeri Malang \\ e-mail: *11rizky.kurniawan@polinema.ac.id, ${ }^{2}$ shintamaharani@polinema.ac.id, ${ }^{3}$ linabudiarti@polinema.ac.id, \\ ${ }^{4}$ umi.khabibah@polinema.ac.id, ${ }^{5}$ waris_sip@polinema.ac.id
}

\begin{abstract}
Abstrak
Kegiatan pengabdian pada masyarakat ini bertujuan untuk memberikan pendampingan pengelolaan media promosi bagi UMKM Prima Laundry guna menjangkau lebih banyak lagi calon konsumen baru. Media promosi yang akan dibuat berupa media promosi online dan offline dikarenakan selama ini sistem promosi masih mengandalkan media offline saja terutama metode Word of Mouth. Pendampingan dengan metode promosi online diharapkan dapat membantu pelaku usaha UMKM yang masih memiliki kesulitan dalam hal promosi usaha. Metode pengabdian dilakukan dengan mengadakan pendampingan pelatihan pembuatan desain media promosi dan pengelolaan media sosial (Instagram), pelatihan pembuatan desain promosi brosur dan spanduk untuk promosi offline. Hasil akhir dari kegiatan ini adalah UMKM mampu menggunakan media promosi online dan offline secara maksimal dan saling mendukung dalam meningkatkan jumlah pelanggan Prima Laundry di Kota Malang, sehingga dapat mewujudkan program pemerintah dalam upaya membangkitkan UMKM.
\end{abstract}

Kata kunci-UMKM, prima laundry, media promosi, online, offline

\section{PENDAHULUAN}

Memiliki asisten rumah tangga akan sangat membantu meringankan pekerjaan rumah. Tetapi pada kenyataannya tidak semua orang menginginkan untuk memiliki asisten rumah tangga karena banyak pertimbangan baik dalam hal karakter manusia, finansial, dan lain sebagainya. Saat ini mencari asisten rumah tangga juga tidaklah mudah karena semakin jarang orang yang mau bekerja sebagai asisten rumah tangga. Selain itu juga semakin mahalnya gaji seorang asisten rumah tangga. Meskipun saat ini banyak orang yang tidak memiliki asisten rumah tangga tetapi tidak menjadi beban berat bagi seseorang meskipun dengan segudang aktivitasnya. Meskipun sudah ada teknologi berupa mesin cuci, tetapi untuk menyetrika baju masih menjadi beban bagi banyak orang. Ditambah lagi dengan padatnya kesibukan.

Telah banyak pelaku bisnis yang membuka usaha Laundry, tetapi tidak semua orang tertarik untuk menggunakan jasa Laundry karena dinilai terlalu lama pelayanannya dan tidak maksimal hasil kerjanya. Prima Laundry adalah sebuah usaha yang bergerak dibidang jasa pencucian pakaian (Laundry). Dinamakan Prima Laundry karena pemilik ingin memberikan pelayanan yang prima kepada pelanggan. Prinsip yang dipegang adalah melayani dengan cepat, bersih, dan tepat waktu. Jika usaha Laundry lain membutuhkan waktu 3-5 hari kerja, tidak demikian halnya dengan Prima Laundry. Excellent service menjadi motto utama bagi Prima Laundry. Waktu yang ditargetkan oleh usaha ini adalah 1-3 hari. Antar jemput Laundry masih dilakukan sendiri oleh sang pemilik usaha untuk proses pencucian sampai dengan penyetrikaanpun juga masih dilakukan oleh sang pemilik meskipun telah memiliki karyawan. Usaha yang masih rintisan ini dijalankan oleh pemilik dengan penuh kerja keras, sehingga promosi usaha sering terabaikan.

Promosi adalah suatu komunikasi pemasaran, artinya aktifitas pemasaran yang berusaha menyebarkan informasi, mempengaruhi/membujuk, dan atau mengingatkan pasar sasaran atas perusahaan dan produknya agar bersedia menerima, membeli dan loyal pada produk yang ditawarkan perusahaan yang bersangkutan[1]. Promosi memberi penjelasan dan meyakinkan calon konsumen mengenai barang dan jasa dengan tujuan untuk memperoleh perhatian, mendidik, mengingatkan dan meyakinkan calon konsumen [2]. Sedangkan, iklan bersifat menjangkau masyarakat luas (masal), tidak pribadi tapi secara langsung dengan audience (impersonal) dan dapat menyampaikan gagasan secara menyakinkan dan menimbulkan efek yang dramatif (ekspresif) [3]. Tujuan dari promosi penjualan adalah untuk 
menginformasikan, membujuk, dan mengingatkan kembali masyarakat [4].

Untuk meningkatkan jumlah pelanggan, maka diperlukan sebuah pendampingan dalam menjalankan dan mengelola media promosi. Promosi usaha yang dilakukan selama ini adalah dari mulut ke mulut dan belum memiliki media promosi yang layak. Oleh karena itu diperlukan sebuah media promosi baik secara online maupun offline. Media promosi online berupa pembuatan akun Instagram beserta iklan pada Instagram dengan layout semenarik mungkin.

Media promosi ini diharapkan dapat membantu usaha yang dijalankan oleh Prima Laundry agar dapat menarik lebih banyak pelanggan dan meningkatkan volume penjualan jasa. Peningkatan volume penjualan merupakan pencapaian yang dinyatakan secara kuantitatif dari segi fisik atau volume atau unit suatu produk [5].

\section{METODE}

Kegiatan pengabdian pada masyarakat ini dilaksanakan sejak bulan April sampai dengan Mei dan bertempat di Prima Laundry yang beralamat di Perum Asabri Bumiayu Indah Blok B/9 Kota Malang. Pendekatan yang ditawarkan adalah dengan mengadakan pendampingan pembuatan desain media promosi offline dan online beserta pengelolaan media promosi online (Instagram). Pembuatan media promosi offline berupa brosur yang akan didampingi dalam proses pembuatannya mulai dari desain, cetak sampai dengan pembagian brosur kepada calon konsumen. Sedangkan untuk media promosi online telah dibuat akun Instagram Prima Laundry dengan feed semenarik mungkin dan dengan jumlah followers sebanyak mungkin.

Selama proses desain Ig Feeds, spanduk dan brosur, tim mendampingi baik secara online maupun offline. Selain itu, juga dilakukan pendampingan dalam menjalankan dan mengelola media tersebut. Media promosi ini diharapkan dapat membantu usaha yang dijalankan oleh Prima Laundry agar dapat menarik lebih banyak pelanggan di Kota Malang.

\subsection{Tahapan Review}

Tahap yang pertama dilakukan adalah memahami permasalahan yang dialami oleh UMKM Prima Laundry yang masih sangat sederhana proses pengelolaannya karena dikelola sendiri oleh sang pemilik yakni Ibu Rini dan Bapak Bandi. Mulai dari antar jemput, proses pengerjaan, dan lain-lain dikelola oleh owner. Oleh karena itu, untuk media promosi menjadi terabaikan karena kesibukan sang pemilik usaha, sehingga promosi yang dilakukan masih dari mulut ke mulut. Oleh karenanya diperlukan sebuah media promosi untuk membantu mempromosikan usaha tersebut.

\subsubsection{Gambar dan tabel}

Gambar berikut merupakan hasil desain dari kegiatan pendampingan pembuatan media promosi online dan offline.

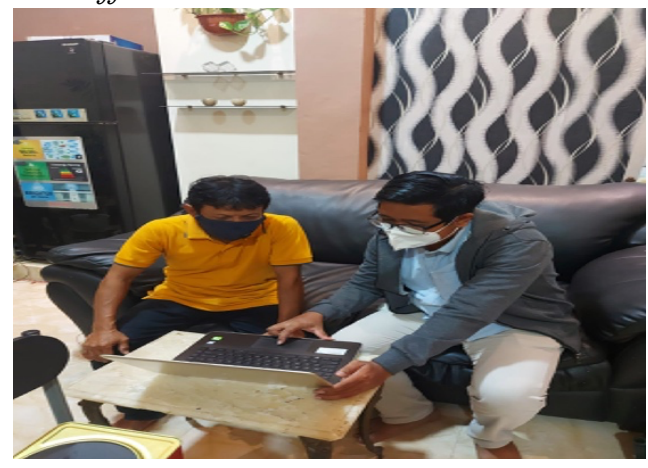

Gambar 1 Proses Pendampingan Pengelolaan Media Online

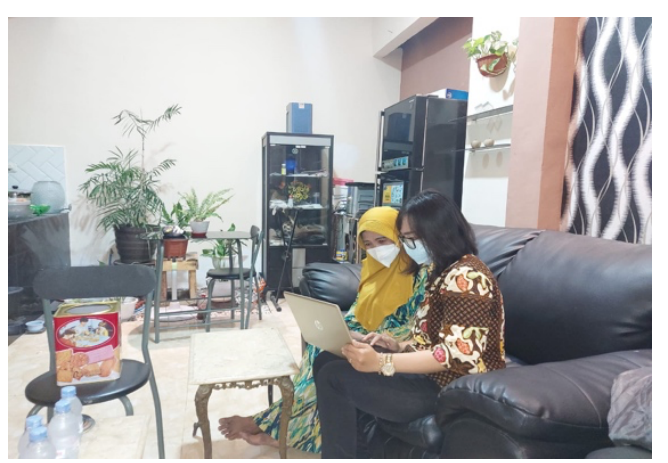

Gambar 2 Proses Pendampingan Pengelolaan Media Online

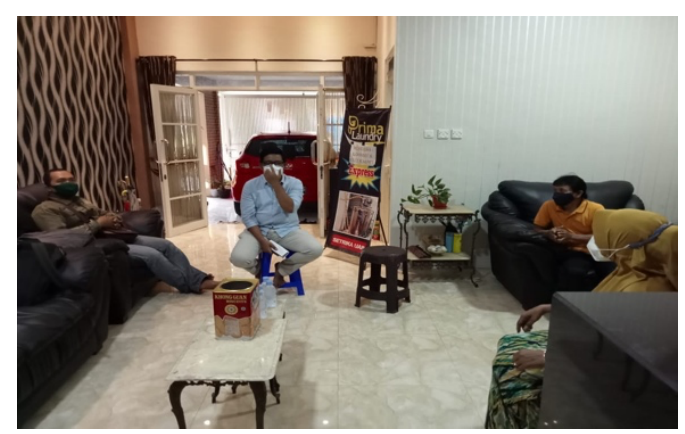

Gambar 3 Diskusi Pengelolaan Media Online 


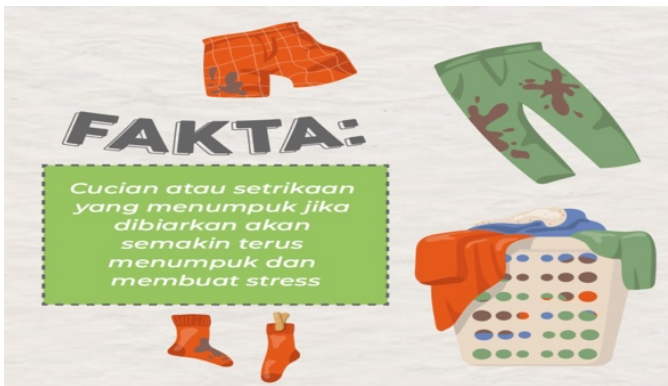

Gambar 4 Hasil pembuatan Ig Feeds

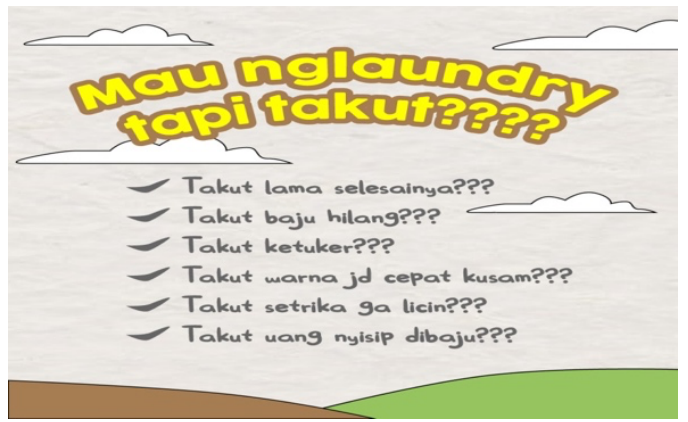

Gambar 5 Hasil Pembuatan Ig Feeds

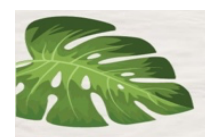

Nefjak USEh Lruatir

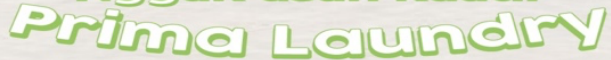
solusinya

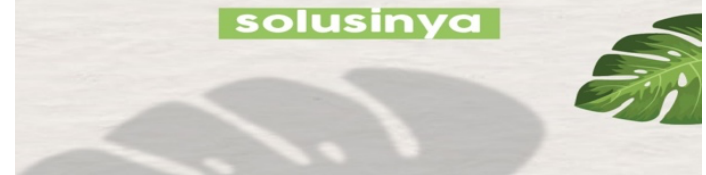

Gambar 6 Hasil Pembuatan Ig Feeds

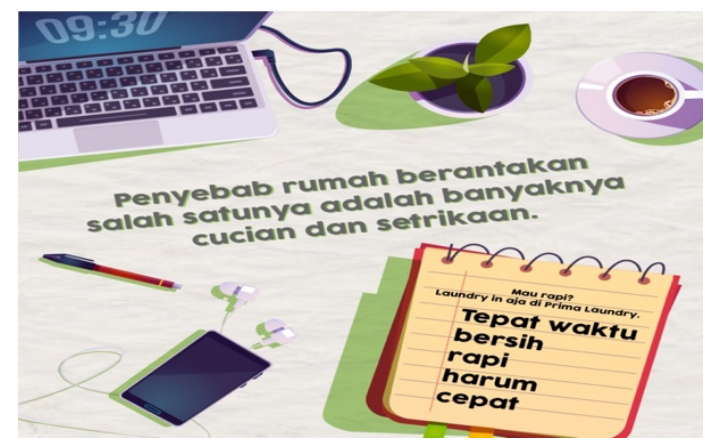

Gambar 7 Hasil Pembuatan Ig Feeds

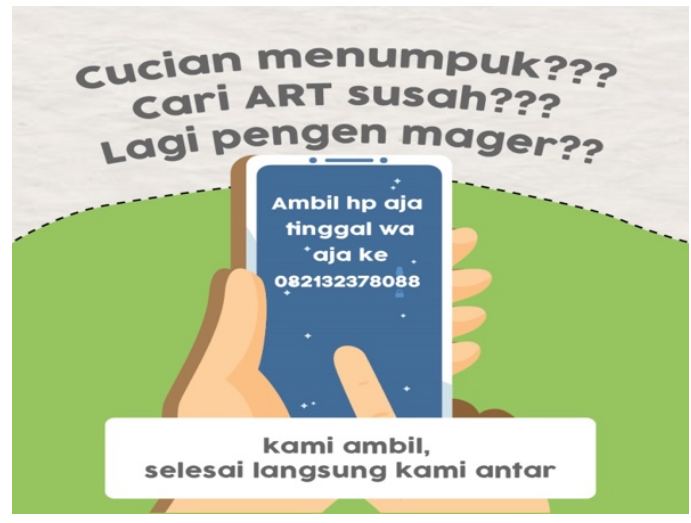

Gambar 8 Hasil Pembuatan Ig Feeds

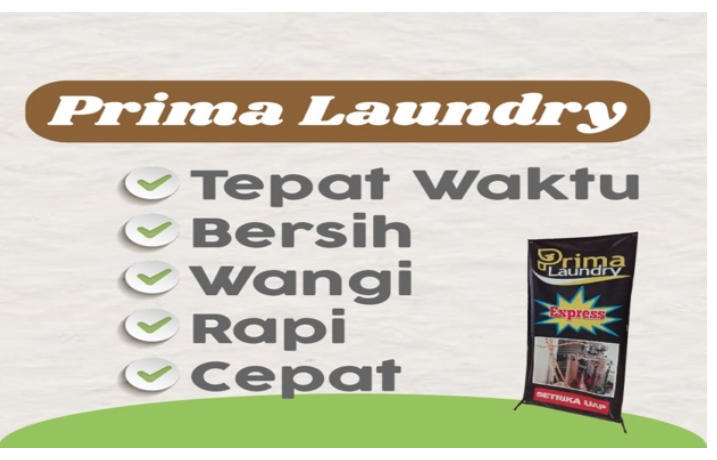

Gambar 9 Hasil Pembuatan Ig Feeds

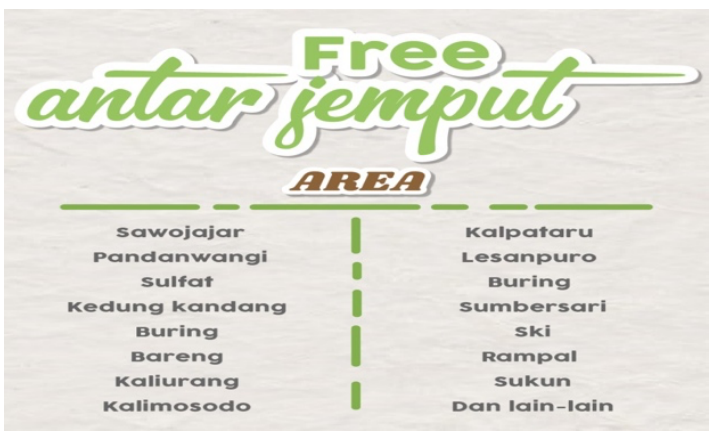

Gambar 10 Hasil Pembuatan Ig Feeds

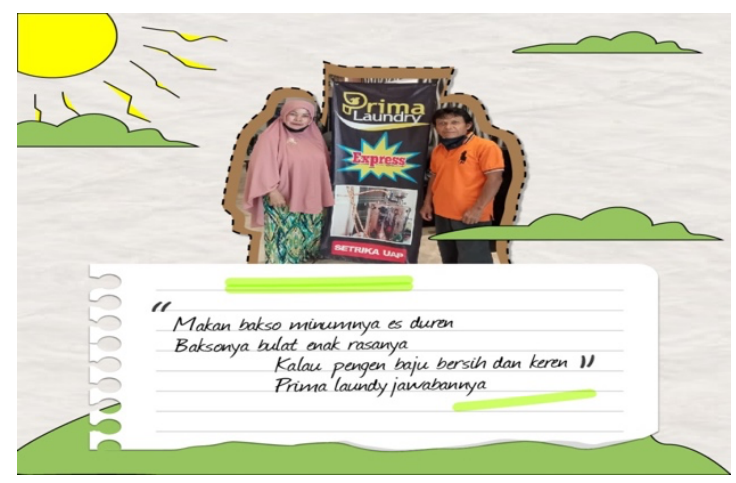

Gambar 11 Hasil Pembuatan Ig Feeds 


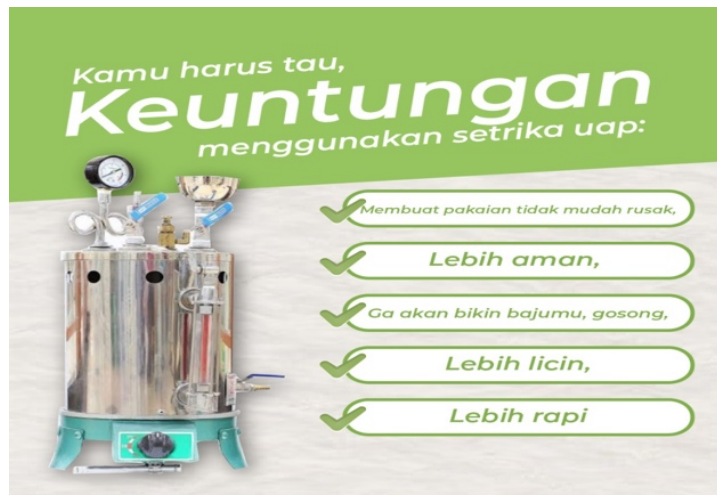

Gambar 12 Hasil Pembuatan Ig Feeds

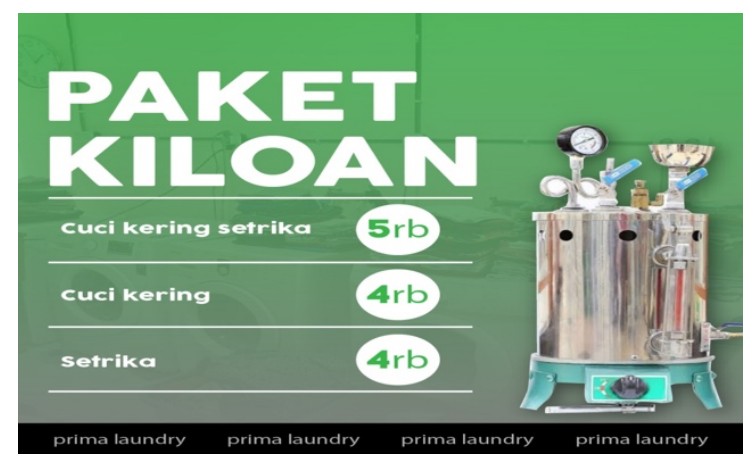

Gambar 13 Hasil pembuatan Ig Feeds

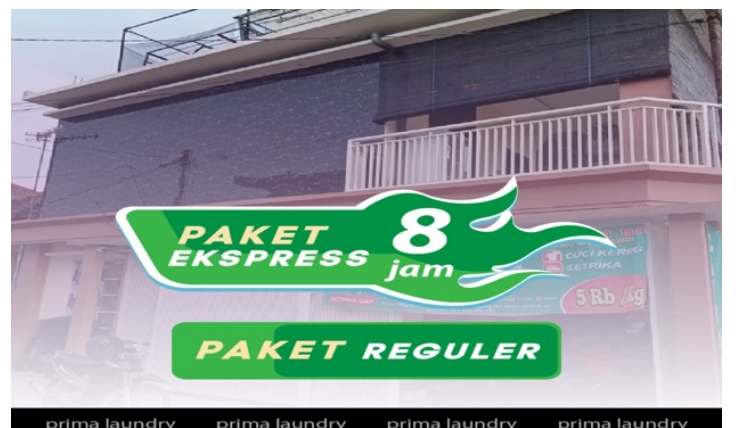

Gambar 14 Hasil pembuatan Ig Feeds

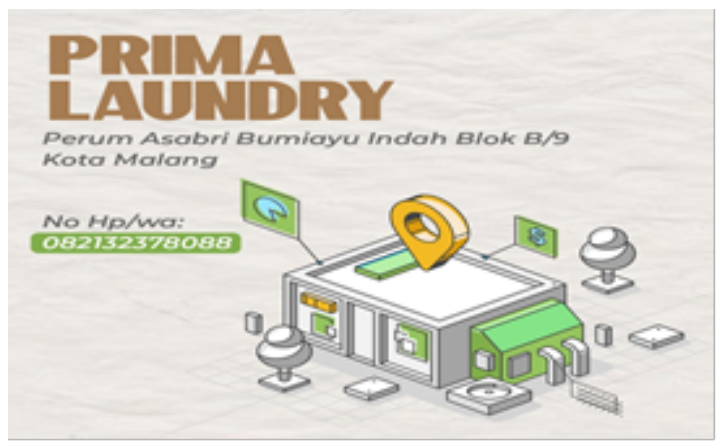

Gambar 15 Hasil pembuatan Ig Feeds

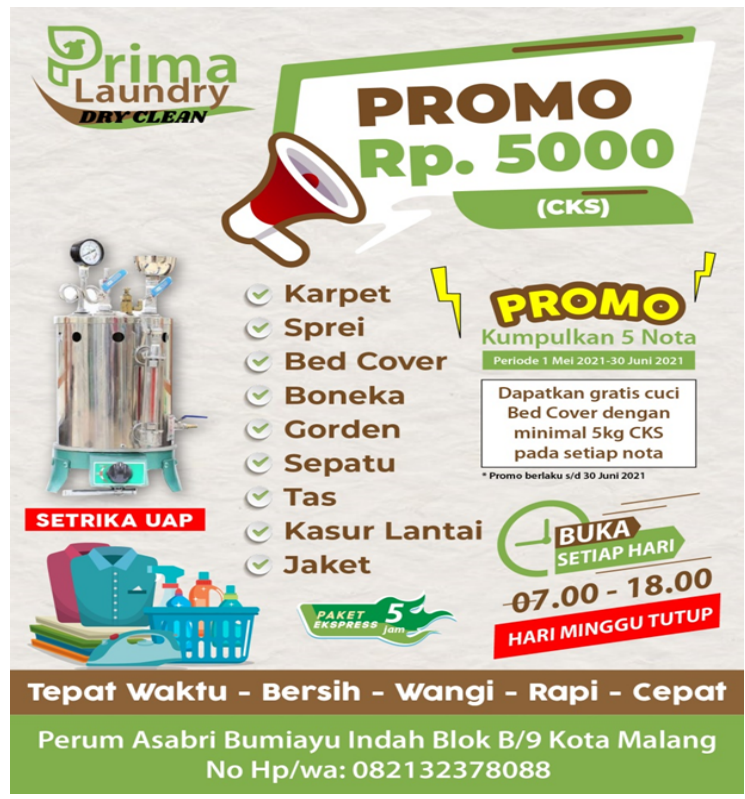

Gambar 16 Hasil Desain Brosur
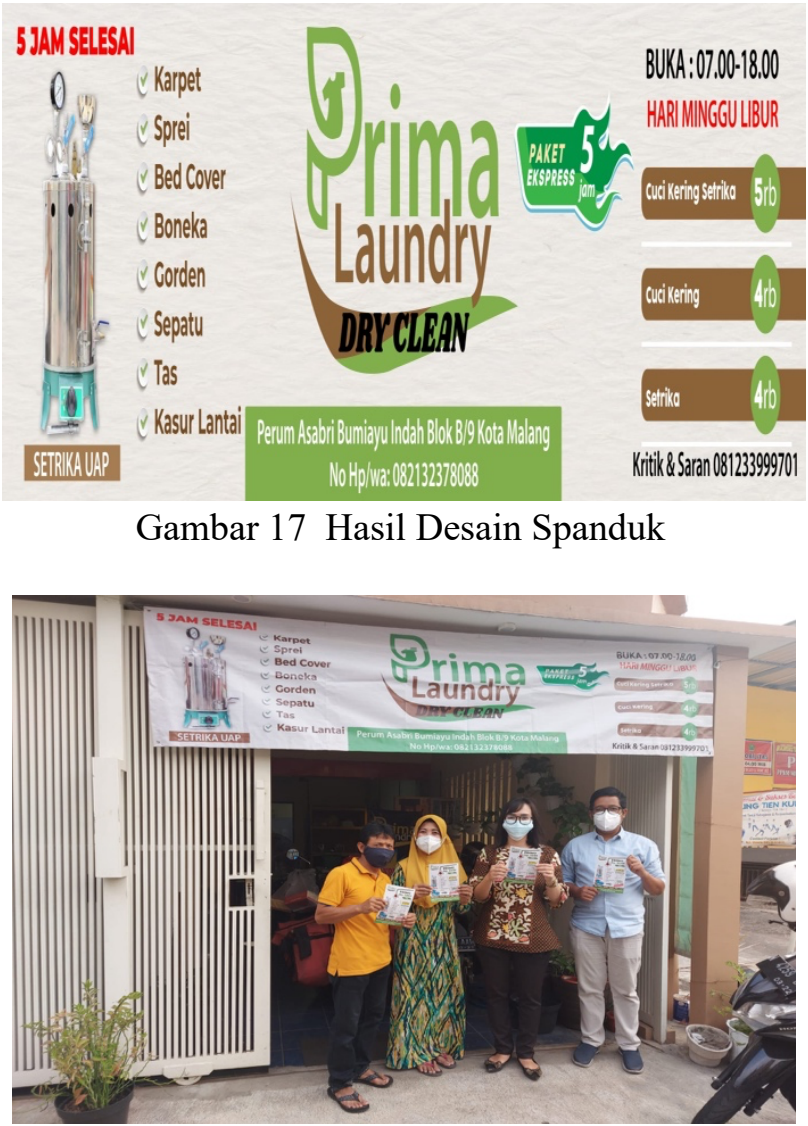

Gambar 18 Hasil Cetak Spanduk dan Brosur

\section{HASIL DAN PEMBAHASAN}

Hasil yang dicapai dari kegiatan pengabdian pada masyarakat ini adalah mengaplikasikan ilmu dan pengetahuan tentang strategi promosi online dan offline dalam bentuk kegiatan pendampingan 
pengelolaan media promosi di Instagram mulai dari pembuatan Ig Feeds, pembuatan akun email, akun Instagram, mencari followers, mengelola Ig Story dan beranda, membalas pesan masuk, dan lain sebagainya.

Kegiatan ini juga menambah pengalaman dan ilmu bagi UMKM Prima Laundry khususnya dalam hal promosi online mengingat promosi yang dilakukan masih secara offline dan lebih memprioritaskan Word of Mouth. Selain itu, kegiatan ini bermanfaat untuk mengaplikasikan kreatifitas pelaku usaha UMKM Prima Laundry dalam membuat desain feeds, brosur, dan spanduk sesuai dengan keinginan. Hasil dari kegiatan pengabdian pada masyarakat ini akan tampak hasilnya apabila secara konsisten ilmu yang diberikan dipergunakan secara maksimal tidak hanya terhenti sampai dengan selesai pelaksanaan pengabdian pada masyarakat berupa pendampingan kepada UMKM saja. Oleh karenanya harus dimaksimalkan promosi online dan offline yang telah dibuat selama kegiatan ini berlangsung.

Tabel 1 kegiatan pengabdian kepada masyarakat

\begin{tabular}{|c|c|c|c|}
\hline Lokasi & Waktu & Jenis Kegiatan & Keberhasilan(\%) \\
\hline Bumiayu & $\begin{array}{c}2 \\
\text { Minggu }\end{array}$ & $\begin{array}{l}\text { Pendampingan } \\
\text { Pembuatan } \\
\text { Desain Ig Feeds, } \\
\text { Brosur, dan } \\
\text { Spanduk }\end{array}$ & 98 \\
\hline Bumiayu & 1 Hari & $\begin{array}{c}\text { Pembuatan akun } \\
\text { email }\end{array}$ & 100 \\
\hline Bumiayu & 1 Hari & $\begin{array}{l}\text { Pembuatan akun } \\
\text { Instagram }\end{array}$ & 90 \\
\hline Bumiayu & $\begin{array}{c}2 \\
\text { Minggu }\end{array}$ & $\begin{array}{c}\text { Pengelolaan } \\
\text { akun Instagram }\end{array}$ & 80 \\
\hline Bumiayu & 2 Hari & $\begin{array}{l}\text { Pencetakan } \\
\text { brosur dan } \\
\text { spanduk }\end{array}$ & 100 \\
\hline
\end{tabular}

\section{KESIMPULAN}

Pengabdian pada masyarakat ini dilaksanakan pada UMKM Prima Laundry yang beralamat di Perum Bumiayu Indah Blok B 09 Bumiayau Kota Malang. Tujuan dari kegiatan Pengabdian pada masyarakat ini adalah membantu pelaku usaha UMKM untuk dapat mengembangkan strategi promosi online dan offline dikarenakan selama ini masih menggunakan strategi offline saja, terutama Word of Mouth.

Pendampingan pembuatan media promosi ini berlangsung secara lancar dan pemilik usaha sangat antusias dalam mendapatkan pendampingan meskipun terdapat keterbatasan waktu dikarenakan pandemi Covid 19. Ilmu yang diperoleh dari kegiatan ini diaplikasikan untuk membuat desain Ig Feeds dan desain brosur, serta spanduk yang dipergunakan untuk media promosi. Hasil yang didapatkan dari kegiatan pengabdian kepada masyarakat ini adalah sebagai berikut:

1. Mengaplikasikan ilmu dan pengetahuan tentang strategi promosi online dan offline

2. Menambah pengalaman dan ilmu bagi UMKM Prima Laundry khususnya dalam hal promosi online

3. Mengaplikasikan kreatifitas pelaku usaha UMKM Prima Laundry dalam membuat desain feeds, brosur, dan spanduk sesuai dengan keinginan.

Oleh karenanya diperlukan kegiatan yang berkelanjutan agar hasil dari kegiatan pendampingan pembuatan media promosi ini dapat dipergunakan secara optimal guna meningkatkan volume penjualan jasa Laundry.

\section{SARAN}

Kegiatan Pengabdian kepada Mayarakat ini dilakukan dengan periode waktu yang terbatas mengingat adanya hambatan dikarenakan pandemi Covid 19. Meskipun kegiatan dilakukan dengan periode yang terbatas hendaknya ilmu dan pengetahuan yang diberikan tidak berhenti sampai kegiatan ini berakhir tetapi dapat diaplikasikan secara berkesinambungan, serta produk yang merupakan outcome dari kegiatan ini dapat dimanfaatkan semaksimal mungkin untuk mendongkrak penjualan jasa laundry.

\section{UCAPAN TERIMA KASIH}

Terimakasih kepada Polinema atas dukungan pendanaan sehingga kegiatan pengabdian pada masyarakat dapat terselenggara dengan baik. Terimakasih kepada Bapak Bandi dan Ibu Rini selaku pemilik Prima Laundry atas kerjasama selama ini terutama dalam suksesnya kegiatan PPM. Semoga outcome yang dihasilkan dapat bermanfaat untuk kemajuan Prima Laundry.

\section{DAFTAR PUSTAKA}

[1] Tjiptono, Fandi, 2001, Strategi Pemasaran, Edisi Ketiga, Cetakan Pertama, Andi Offset Yogyakarta.

[2] Buchari, Alma, 2006, Manajemen Pemasaran dan Pemasaran Jasa, Alfabeta, Bandung. 
[3] Darmesta, Basu Swastha, 2002, Pemasaran Modern, Liberty, Yogyakarta.

[4] Tjiptono, F., \& Diana, A., 2015, Pelanggan Puas? Tak Cukup! Plus: Contoh Spesifik Riset Kepuasan Dan Ketidakpuasan Pelanggan, Strategi Mewujudkan Kepuasan Pelanggan, CV Andi Offset, Yogyakarta.

[5] Rangkuti, Freddy, 2009, Strategi Promosi Yang Kreatif Dan Analisis Kasus Integrated Marketing Communication, Anggota IKAPI, Jakarta. 